\title{
N-methyl-D-aspartate (NMDA) mediates vascular relaxation via nitric oxide (NO) in rats but not in mice
}

\author{
Francesco Crespi
}

Biology Dept, Neurosciences CEDD GlaxoSmithKline, Medicines Research Centre, Verona, Italy. Email: Francesco.M.crespi@GSK.com

Received 26 April 2010; revised 7 June 2010; accepted 28 June 2010.

\begin{abstract}
Amperometric studies have indicated that substance $P$ as well as NMDA stimulates release of NO in rat aortic rings. These data have been confirmed by functional observations of vaso-relaxant action of NMDA within noradrenaline pre-contracted aortic rings, supporting the presence of NMDA receptor in rat aortic rings. It is known that the enzyme endothelial NO synthase (eNOS) mediates vasodilatation not only in rats, but also in C57BL6 mice aortic ring, indicating that in this blood vessel NO is the endogenous endothelium-derived vasodilator. In this work, amperometry together with specifically nitrites insensitive micro-biosensors have been applied to examine the effect of NMDA and substance $P$ upon NO release in rat and in two strains of mice aortic rings. The electrochemical data monitored demonstrate that NMDA mediates vascular relaxation via NO in rats but not in mice. These results are supported by functional data, therefore they suggest that NMDA receptors are "not responding" within these experimental conditions in mice aortic rings.
\end{abstract}

Keywords: Nitric Oxide; Amperometry; Carbon Fibre Micro-Electrodes; Mice; Rats; Aortic Rings; N-MethylD-Aspartate; Substance P

\section{INTRODUCTION}

In vivo studies have demonstrated the possibility to monitor NOx [mixture of nitrites and nitrates, i.e. metabolites of nitric oxide (NO)] by means of in vivo microdialysis in rat brain [1]. More recently, direct and selective measurement of NO has been performed by means of nitrites and nitrates insensitive carbon fibre micro-electrodes (mCFE) used as micro-biosensors in association with an electrochemical methodology such as amperometry [2-4].

In particular, these two in vivo electrochemical meth- odologies have shown that:

1) Infusion of N-methyl-D-aspartate (NMDA) via the microdialysis probe resulted in a dose-dependent increase in cerebellar NOx release. This increase was prevented by prior administration of an NMDA-receptor antagonist (i.e. AP5) or the NO synthase inhibitor $\mathrm{N}-\mathrm{G}$-nitroarginine. These results provided direct evidence for NOx release in response to NMDA receptor activation in the cerebellar cortex of adult rat [1].

2) Amperometric analyses performed in the striatum of anaesthetized adult rats, also showed that NMDA stimulates cerebral $\mathrm{NO}$ release in vivo and that treatment with NMDA receptor antagonists or NOS inhibitors prevented the NMDA-induced NO related signal. Furthermore, amperometric experiments performed together with selective $\mathrm{NO}$ detecting $\mathrm{mCFE}$ in rat aortic rings, did provide evidence that oxidation of $\mathrm{NO}$ can be directly and selectively measured within the lumen of such peripheral tissue $[3,4]$. In particular, addition of substance $\mathrm{P}$ [an amidated peptide which is a potent endothelium dependent vasodilator as it activates the enzyme nitrogen monoxide synthase in endothelial tissue (eNOS)] resulted in increased $\mathrm{NO}$ levels in rat aortic rings [3,4]. Accordingly, addition of NMDA to this peripheral tissue resulted in electrochemical activation, i.e. punctual increase of amperometric NO signal together with concomitant vascular relaxation (functional activity) $[3,4]$. These original data have then demonstrated that NMDA can stimulate NO release in rat aortic rings.

Previous works have shown that eNOS mediates vasodilatation also in C57BL6 mice aortic rings [5]. Indeed, in this tissue acetylcholine induced an endothelium-dependent relaxation that was inhibited by $\mathrm{N} \omega$-L-nitro-arginine, indicating that in this blood vessel NO is the sole endogenous endothelium-derived vasodilator [6]. Therefore, in mice, as well as in rats, NO has been implicated in the regulation of blood pressure [5].

In the present work, the feasibility of using amperometry and $\mathrm{NO}$ sensitive $\mathrm{mCFE}$ to analyze $\mathrm{NO}$ activ- 
ity not only in rats but also in mice aortic rings has been tested.

\section{METHODS}

Naïve adult male CD rats (250-280 g) and two strains of mice: C57BL6 mice (20-22 g) and CD1 mice (20-22 g, Charles River) were supplied by Charles-River (Italy) and were kept in temperature- and humidity-controlled rooms $\left(22^{\circ} \mathrm{C}, 50 \%\right)$ with lights on from 0700 to 1900 hours with water and food available ad libitum. All procedures were carried out in accordance with the Italian law (Legislative Decree no.116, 27 January 1992), which acknowledges the European Directive 86/609/EEC, and were fully compliant with GlaxoSmithKline policy on the care and use of laboratory animal and codes of practice. Furthermore, all efforts were made to minimize the number of animals used and their suffering.

Rat aortic rings (approximately $3 \mathrm{~mm}$ in length and $1.5 \mathrm{~mm}$ diameter) and mice aortic rings (approximately $3 \mathrm{~mm}$ in length and $0.5-1 \mathrm{~mm}$ diameter) have been prepared accordingly to the literature [7] and maintained in aerated Krebs with the addition of calcium and glucose. Then, each aortic ring was positioned within the voltammetric well and immersed in $200 \mu \mathrm{l}$ of Krebs as described earlier [4].

The NO sensitive carbon fibre micro electrode (mCFE, $30 \mu \mathrm{m}$ diameter, $3 \mathrm{~mm}$ length) was prepared as previously illustrated in order to avoid detection of nitrites, i.e. NO metabolites having an oxidation potential similar to that of NO: approximately $+700 /+800 \mathrm{mV}$ [8]. Briefly, the micro-biosensor was coated with Nafion, a sulphonated polymer that repels anions (such as nitrites) while allowing the specific oxidative detection of NO $[9,10]$. In addition, the mCFE was electropolymerised with ortho-phenylenediamine (oPD) as described previously [11] in order to improve selectivity by limiting access of large molecules (such as nitrites), to the surface of the biosensor. Then, the $\mathrm{mCFE}$ was positioned in direct contact with the endothelium inside the lumen of the vessel ring under light microscopy (Figure 1). In such way "endothelial" amperometric experiments could be performed as reported earlier at the oxidation potential of $+800 \mathrm{mV}[3,4]$ by means of the voltammetric apparatus "MicroAutolab II" (EcoChemie, The Netherland) [10]. Then two different current values were examined:

1) Basal current level expressed in nanoAmperes (nA) due to the oxidation of basal endogenous NO;

2) NO stimulated release, obtained via local application of:

- A chemical known to have vascular dilating properties such as Substance P [12];

- NMDA that has been described able to stimulate NO release in rat aortic rings $[3,4,13]$.

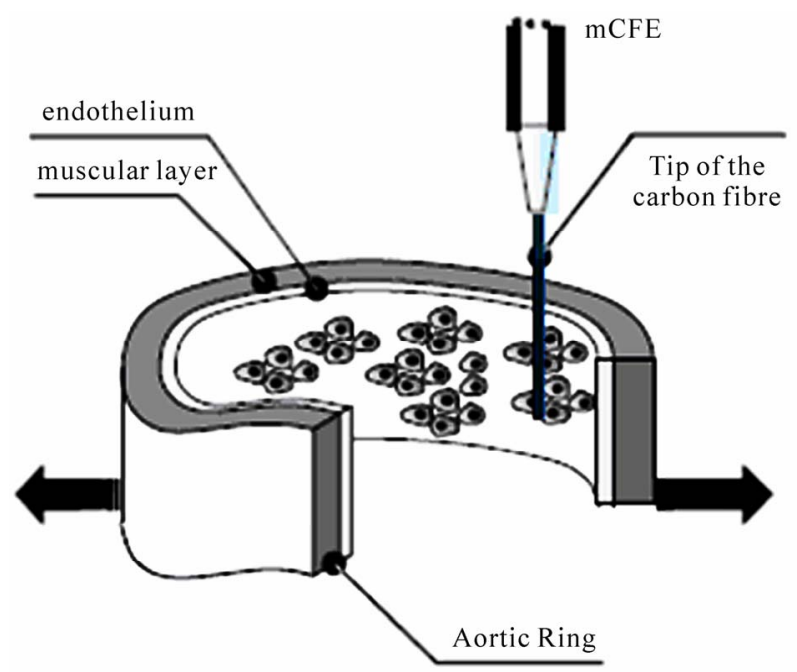

Figure 1. Functional and amperometric preparation for mice aortic rings immersed within $200 \mu \mathrm{l}$ Krebs (test sample). The active tip (carbon fibre) of the Nafion-oPD CFE is parallel and in contact with the endothelium of the aortic ring. Arrows emulate the apparatus for functional studies as described previously $[3,4]$.

\section{RESULTS \& DISCUSSION}

It appeared that basal amperometric NO related current levels can be monitored in rats as well as in mice aortic rings. In particular, these amperometric NO basal current levels were similar within the two types of mice aortic rings: approximately $2.61 \pm 0.52$ nanoAmperes $(\mathrm{nA})$ in C57BL6 and $3.49 \pm 0.82$ in CD1 mice while it was about $0.22 \pm 0.03 \mathrm{nA}$ in $\mathrm{CD}$ rats aortic rings.

Higher endothelial NO levels in mice than in rat aortic rings could be related to the smaller diameter of the lumen in the former specie in which therefore endothelial NO could more easily [and possibly more profusely] enter in contact with the mCFE. This will allow the mCFE to capture more NO within the reduced time-span [from fraction of second to few seconds] in which this highly reactive, short living molecule is present in the aortic lumen [14-16].

Successively, stimulation of the release of NO was performed as described earlier [3,4]. Briefly, it consisted in a single addition of $5 \mu \mathrm{l}$ Substance P $1 \mathrm{mM}$ or NMDA $0.1 \mathrm{mM}$ (or $5 \mu \mathrm{l}$ of the vehicle Krebs, control experiment) to each mouse or rat aortic ring immersed within $200 \mu \mathrm{l}$ of Krebs in the voltammetric well. Thus, in the well, the final concentration of Substance P and NMDA was 25 $\mu \mathrm{M}$ and $2.5 \mu \mathrm{M}$, respectively. The addition was performed during the amperometric scan that was lasting 300 seconds: precisely it was done at the $50^{\text {th }}$ second of the amperometric measurement [3,4].

Data obtained indicated that substance $\mathrm{P}$ was able to significantly increase the basal NO related amperometric 
current levels monitored in rats and in mice aortic rings, while NMDA did induce significant release of NO in rats aortic rings only. More precisely, addition of NMDA within mice aortic rings resulted in a signal similar to that obtained when vehicle (Krebs) was added to the same aortic rings (see Figure 2 and corresponding Table 1).

For an easier comparison between rats and mice values in Figure 2 data are expressed in percent of control (addition of Krebs) while in Table 1 amperometric NO levels are expressed in real current values (nA).

Therefore, the present data demonstrate that: 1) Substance $\mathrm{P}$ stimulated NO release within aortic rings of both CD1and C57BL6 mice as well as in rats; 2) in contrast to data monitored in rat aortic rings, NMDA did not cause NO release in aortic rings from both type of mice (see Figure 2 and Table 1). Precisely, NMDA addition in the mice test samples was followed by a reduced, transient increase of the amperometric current similar to that obtained when Krebs (vehicle) was added (see Table 1). This small increase could be a nonspecific signal related to mechanical stimuli given to the tissue while performing the local application of compounds. On the other hand, this action could be sufficient to activate synthesis and release of a reduced amount of NO.

Thus, these ex vivo data indicate that NMDA was unable to stimulate a significant NO release when added to mice aortic rings, suggesting lack of NMDA receptor functioning or lack of or sensitivity to the [large] dose of NMDA applied in this mice peripheral tissue.

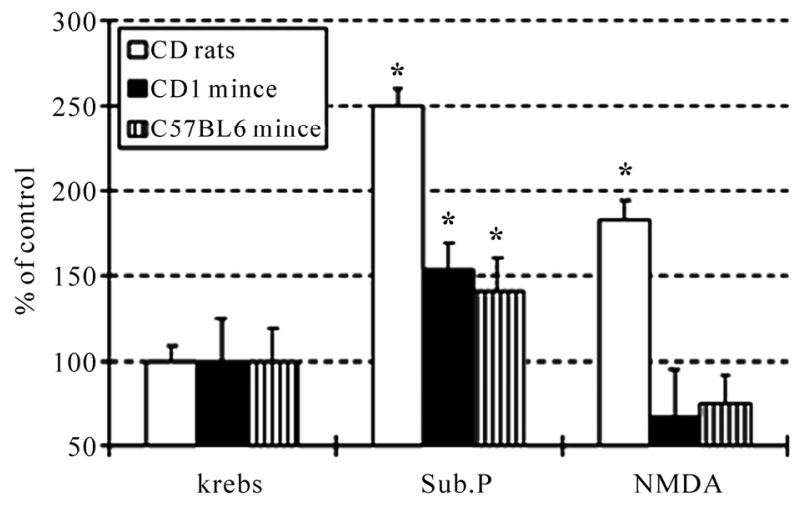

Figure 2. Mean of the size of the amperometric transient peaks monitored in CD rat, CD1 and C57BL6 mice aortic rings to which Krebs (vehicle, $5 \mu \mathrm{l})$, Substance P $(25 \mu \mathrm{M})$ or NMDA $(2.5 \mu \mathrm{M})$ were added $(\mathrm{n}=6$ each compound). Data are expressed in $\%$ of control (addition of Krebs), mean \pm S.D.; however, statistics were calculated from the raw data using ANOVA with STATISTICA software version 6.0. In the case of statistically significant differences between mean values produced by drug treatments versus controls (vehicle treatment) main factor Dunnet post-hoc test was applied. Statistical significance was set at $\mathrm{p}<0.05\left[{ }^{*}\right]$.
Table 1. Mean of the size (current level) of the transient amperometric NO related peaks resulting from addition of Krebs (vehicle, $5 \mu \mathrm{l})$, Substance $\mathrm{P}(25 \mu \mathrm{M})$ or NMDA $(2.5 \mu \mathrm{M})$ to aortic rings of CD1 mice, C57BL6 mice or CD rats $(n=6$ each). Data are expressed in $n A$, mean \pm S.D. ${ }^{*} p<0.05$ Dunnett's test.

\begin{tabular}{cccc}
\hline COMPOUND & $\begin{array}{c}\text { CD1 mice } \\
\text { Current level nA }\end{array}$ & C57BL6 mice & CD rats \\
\hline Substance P & $\mathbf{8 . 4 7} \pm 1.01^{*}$ & $\mathbf{5 . 1 8} \pm 0.78^{*}$ & $\mathbf{0 . 7 5} \pm 0.08^{*}$ \\
NMDA & $\mathbf{3 . 6 8} \pm 0.47$ & $\mathbf{2 . 7 7} \pm 0.34$ & $\mathbf{0 . 5 5} \pm 0.06^{*}$ \\
Krebs & $\mathbf{4 . 1 5} \pm 0.79$ & $\mathbf{2 . 7 6} \pm 0.52$ & $\mathbf{0 . 3 0} \pm 0.03$ \\
\hline
\end{tabular}

Functional studies [17] have been undertaken in order to verify this hypothesis: in particular, the already proposed feasibility of combining amperometry with functional test [3] has been further verified. Briefly, aortic rings from both type of mice were maintained within Krebs in the voltammetric well and were contracted via addition of $1 \mu \mathrm{M}$ noradrenaline (NA) (see Figure 3(a): arrow a). Successively the active tip (3 $\mathrm{mm}$ length) of the NO sensitive mCFE was positioned parallel and in contact with the ring endothelium as described above (figure 1 top). Then nitrites $100 \mu \mathrm{M}$ and NO $6.6 \mu \mathrm{M}$ (Figure 3(a): arrows b and c, respectively) were consecutively added to the well.

It appeared that in both strains of mice:

1) Addition of nitrites did not alter the contracted state of the aortic ring as well as the amperometric current monitored concomitantly (see Figure 3(a) and (b), arrows b).

2) Successive addition of NO was followed by vaso-relaxation and concomitant significant increase of the amperometric signal (Figure 3(a) and (b), arrow c).

These data confirm that NO is the compound responsible for vascular relaxation [6] and that its presence as well as its vaso-relaxing efficacy can be directly monitored by means of amperometric measurements associated with functional analysis.

In successive analysis, $1 \mu \mathrm{M}$ NA pre-contracted rats or mice aortic rings were prepared in Krebs at $37^{\circ} \mathrm{C}$ as described earlier [7,17]. Then acetylcholine ( $\mathrm{ACh}$, used as a reference compound [7] or NMDA at various concentrations (from $1 \mathrm{nM}$ to100 $\mu \mathrm{M}$ ) were added. This resulted in the expected ring relaxation in response to Ach in both rats and mice aortic rings tested. In contrast, no relaxation was monitored in mice aortic rings in response to any NMDA concentration, while rats aortic rings appeared to be responsive to the NMDA challenge (see Figure 4). This allows suggesting that NMDA addition to mice aortic rings does not stimulate NO release, therefore supporting the electrochemical data presented above. 


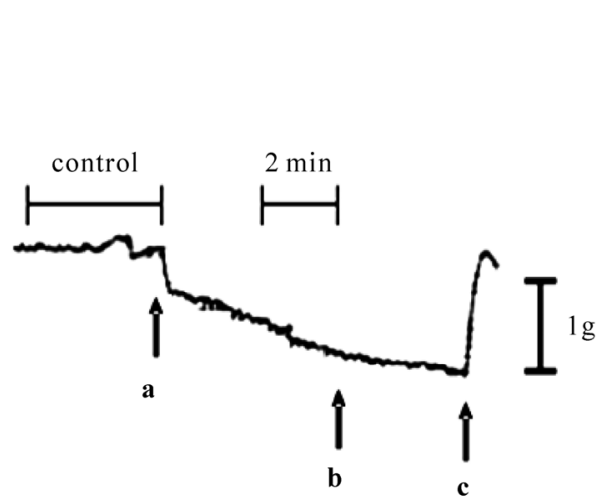

(a)

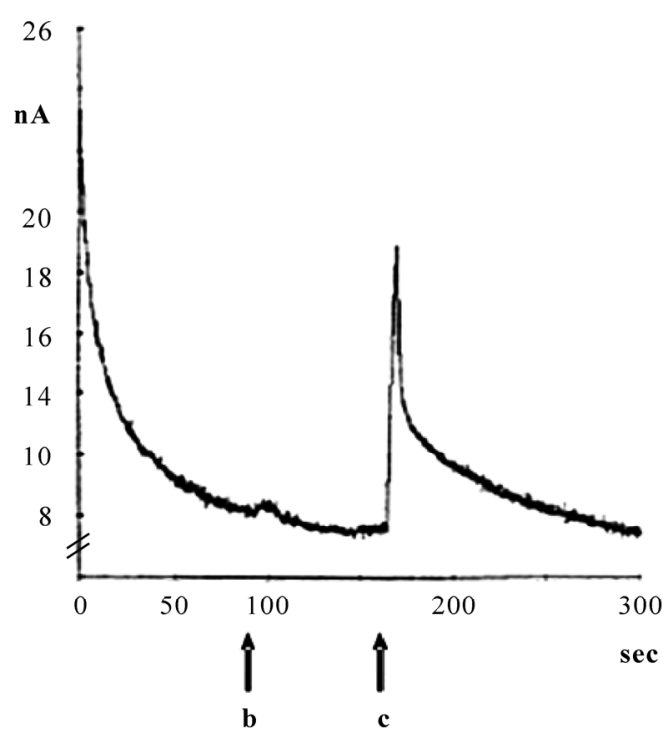

(b)

Figure 3. (a) contracting effect of NA $1 \mu \mathrm{M}$ (arrow a) upon an untreated (CONTROL) CD1 mouse aortic ring. Then nitrites $100 \mu \mathrm{M}$ (arrow b) and NO $6.6 \mu \mathrm{M}$ (arrow c), respectively were added to the aortic ring. Note that addition of NO but not addition of nitrites, relaxes the aortic ring. This figure is $n=1$, very similar data have been obtained in aortic ring preparations from other 4 CD1 mice. Similar outcome was monitored in five C57BL6 mice and five rats; (b) concomitant amperometric measurements of the effect of addition of nitrites (arrow b) and NO (arrow c) upon basal current levels. Similar data have been obtained in five CD1, five C57BL6 mice and five rat aortic rings.
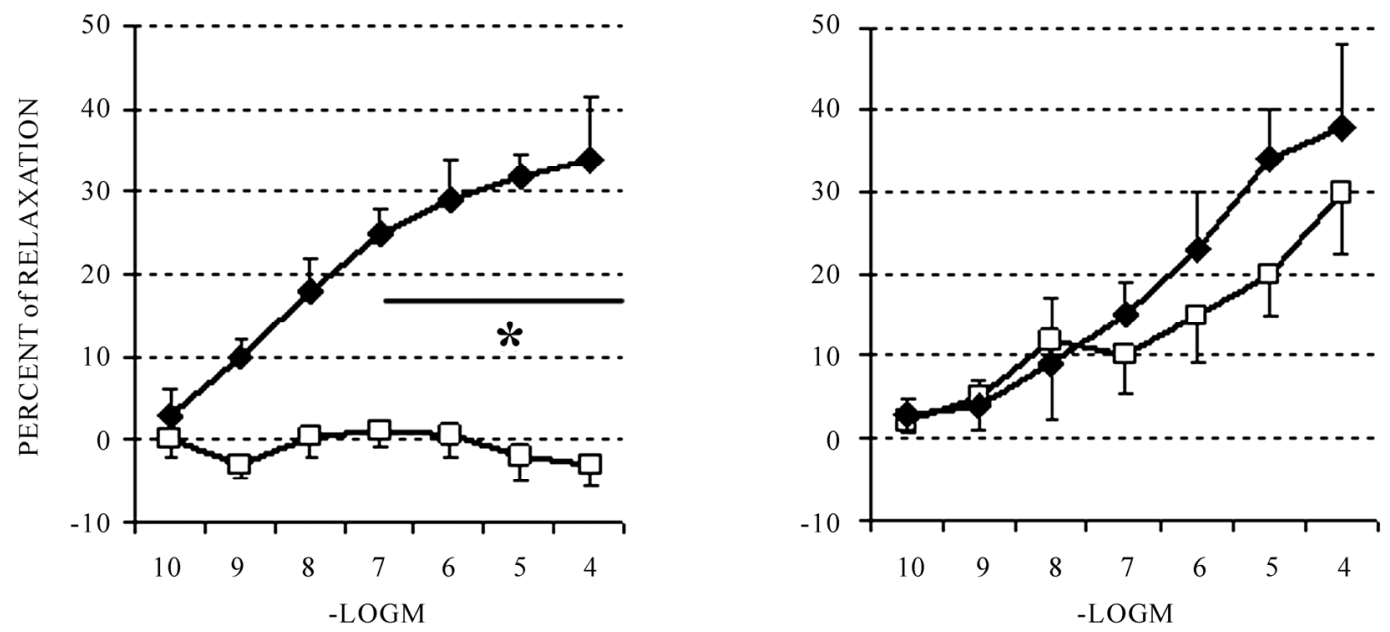

Figure 4. Relaxation of mice [LEFT] or rats [RIGHT] aortic rings pre-contracted with NA $0.1 \mu \mathrm{M}$ following treatment with ACh $(\bullet)$ or NMDA $(\boldsymbol{\square})$ at various concentrations. Data are expressed in \% of relaxation considering zero $\%$ as maximum contraction level of each aortic ring. Mean \pm S.D., $n=5$ aortic rings for each compound tested, $* \mathrm{p}<0.05$ [see above for statistic evaluation].

When the present data are compared with similar experiments performed earlier in rats [4] it appears that NA has to be more concentrated to obtain vascular contraction in mice than in rats i.e. $1 \mu \mathrm{M}$ in mice versus $0.1 \mu \mathrm{M}$ in rats [4]. On the other hand, vasodilatation has been obtained with lower ACh concentration in mice (approximately $15 \%$ or $28 \%$ relaxation with ACh $10 \mathrm{nM}$ or
$1 \mu \mathrm{M}$, respectively) than in rats (approximately $5 \%$ or $18 \%$ relaxation with $\mathrm{ACh} 10 \mathrm{nM}$ or $1 \mu \mathrm{M}$, respectively [3]). These data indicate that higher concentration of NA or lower concentration of $\mathrm{ACh}$ are needed to obtain vascular contraction or vasodilatation in mice, respectively when compared to similar functional tests in rats. Thus, these data further support the hypothesis mentioned 
above about a possible higher "reactivity" of endothelial NO system in mice than in rats. Finally, these data provide direct evidence that amperometry can monitor basal as well as stimulated NO activity within rodents aortic rings and that this electrochemical methodology can be associated with functional vascular studies. In addition, they propose that NMDA directly mediates vascular relaxation via NO in rats but not in mice, suggesting that NMDA receptor could be "functionally" absent in C57BL6 as well as CD1 mice aortic rings.

\section{REFERENCES}

[1] Luo, D., Knezevich, S. and Vincent, S. (1993) NMDA induced NO release: An in vivo microdialysis study. Neuroscience, 57, 897-900.

[2] Crespi, F. (1990) In vivo voltammetry with microbiosensor for analysis of neurotransmitter release and metabolism. Journal of Neuroscience Methods, 34, 53-658.

[3] Crespi, F., Lazzarini, C., Andreoli, M. and Vecchiato, E. (2000) Voltammetric and functional evidence that $\mathrm{N}$-methyl-D-aspartate and substance P mediate rat vascular relaxation via nitrogen monoxide release. Neuroscience Letters, 287(3), 219-222.

[4] Crespi, F., Vecchiato, E., Lazzarini, C. and Gaviraghi, G. (2001) Electrochemical evidence that lacidipine stimulates release of nitrogen monoxide (NO) in rat aorta. Neuroscience Letters, 298(3), 171-174.

[5] Huang, P.L., Huang, Z., Mashimo, H., Bloch, K.D., Moskowitz, M.A. and Fishman, M.C. (1995) Hypertension in mice lacking the gene for endothelial nitric oxide synthase. Nature, 377(21), 239-242.

[6] Chataigneau, T., Feletou, M., Huang, P.L., Fishman, M.C., Duhault, J. and Vanhoutte, P.M. (1999) Acetylcholine-induced relaxation in blood vessels from endothelial nitric oxide synthase knockout mice. British Journal of Pharmacology, 126(1), 219-226.

[7] Furchgott, R.F. (1980) The obbligatory role of endothelial cells in the relaxation of arterial smooth muscle by Acetylcholine. Nature, 288, 373-376.

[8] Privat, C., Lantoine, F., Bedioui, F., Millanvoye, van
Brussel, E., Devynck, J. and Devynck, M.A. (1997) Nitric Oxide production by endothelial cells: Comparison of three methods of quantification. Life Sciences, 61(12), 1193-1202.

[9] Crespi, F., Martin, K.F. and Marsden, C.A. (1988) Measurement of extracellular basal levels of serotonin in vivo using nafion coated carbon fibre microelectrodes combined with differential pulse voltammetry. Neuroscience, 27, 885-898.

[10] Crespi, F. (2009) Anxiolytics antagonize Yohimbineinduced central noradrenergic activity: A concomitant in vivo voltammetry-electrophysiology model of anxiety. Journal of Neuroscience Methods, 180, 97-105.

[11] Friedemann, M.N., Robinson, S.W. and Gerhardt, G.A. (1996) o-Phenylenediamine-Modified Carbon Fiber Electrodes for the Detection of Nitric Oxide. Analitical Chemistry, 68, 2621-2628.

[12] Oldham, C.D., Li, C., Feng, D., Scott, R.O., Wang, W.Z., Moore, A.B., Girard, P.R., Huang, J., Caldwell, R.B., Caldwell, R.W. and May, S.W. (1997) Amidative peptide processing and vascular function. American Journal of Physiology, 273, 1908-1914.

[13] Crespi, F. and Rossetti, Z. (2004) Pulse of Nitric Oxide Release in Response to Activation of N-Methyl-D-Aspartate Receptors in the Rat Striatum: Rapid Desensitisation, Inhibition by Receptor Antagonists and Potentiation by Glycine. Journal of Pharmacology \& Experimental Therapeutics, 309(2), 462-468.

[14] Moncada, S., Palmer, R.M.J. and Higgs, E.A. (1989) Biosynthesis of nitric oxide from L-arginine. A pathway for regulation of cell function and communication. Biochemical Pharmacology, 38, 1709-1715.

[15] Rossetti, Z.L. and Crespi, F. (2004) Inhibition of nitric oxide release in vivo by ethanol. Alcoholism: Clinical Experimental Research, 28, 1746-1751.

[16] Wood, J. and Garthwaite, J. (1994) Models of the diffusional spread of nitric oxide: Implications for neural NO signalling and its pharmacological properties. Journal of Neuropharmacology, 33(11), 1235-1244.

[17] Furchgott, R.F. (1984) The role of endothelium in the responses of vascular smooth muscle to drugs. Annual Review of Pharmacology \& Toxicology, 24, 175-197. 